\title{
Glomerulonephritis in Children: Experience from the Kuwait Renal Centers
}

\author{
K. El-Reshaid ${ }^{a} \quad$ M.M. Kapoor ${ }^{b}$ M.R.N. Nampoory ${ }^{b} \quad$ J.P. Madda ${ }^{c}$ \\ N. Jawad ${ }^{d}$ K.V. Johny ${ }^{a}$ \\ aDepartment of Medicine, Faculty of Medicine, Kuwait University, and Departments of \\ bMedicine, ' Pathology, and dPaediatrics, Ministry of Health, Kuwait
}

\section{Key Words}

Epidemiology · Glomerulonephritis · Kuwait • Nephrotic syndrome

\begin{abstract}
Objective: To study the clinical, pathological, and epidemiological features of childhood steroid-refractory idiopathic glomerulonephritis (SRIGN), i.e., nephrotic syndrome, which failed an 8-week course of prednisone, and secondary forms of glomerulonephritis (GN) in Kuwait. Methods: Data on these two forms of $\mathrm{GN}$ were collected retrospectively from the records of children attending the two renal centers of Kuwait between January 1, 1990, and December 31, 1996. Results: During the 7 years, a total of 80 children were diagnosed to have GN, 56 of whom were Kuwaiti nationals. In the latter group, 34 children had SRIGN. Hence, the calculated annual incidence rate of Kuwaiti children with both GNs was 3.1 per million and that for SRIGN was 1.9 per million children. Histologically, 22 (65\%)
\end{abstract}

\begin{tabular}{ll}
\hline KARGER & (1) 1999 S. Karger AG, Basel \\
Fax +41 61 306 1234 34 & \\
$\begin{array}{l}\text { E-Mail karger@karger.ch } \\
\text { www.karger.com }\end{array}$ & $\begin{array}{l}\text { Accessible online at: } \\
\text { www.karger.com/journals/mpp }\end{array}$
\end{tabular}

of these patients had minimal change, 5 (16\%) focal segmental, 2 (6\%) non-lgA mesangioproliferative, and 1 membranous GN. Congenital nephrotic syndrome, membranoproliferative $\mathrm{GN}$, and $\mathrm{GN}$ secondary to parasitic infestations or microbial infections were not seen in the Kuwaiti children, and nephrotic syndrome secondary to $\lg \mathrm{A}$ glomerulopathy was diagnosed in 1 patient only. Aggressive autoimmune diseases such as systemic lupus erythematosus (SLE) and vasculitis were common. Seven patients had SLE which accounted for $44 \%$ of secondary $\mathrm{GN}$ and for $14 \%$ of all the patients included in the study, while 3 patients were found to have vasculitis. Interestingly, only 3 of the 13 patients with SLE and vasculitis presented with rapidly progressive GN. Conclusions: The pattern of renal disease associated with SRGN in Kuwaiti children is different from that reported from neighboring countries and other Arab states. The homogeneity of the population studied, lack of endemic infections or parasitic infestations, and genetic predisposition may have

Dr. Kamel El-Reshaid

Department of Medicine, Faculty of Medicine

Kuwait University, PO Box 24923

13110 Safat (Kuwait)

Tel. +965 5319596, Fax +965 5318454 
been the underlying factors. Furthermore, the high incidence of the insidious kidney-limited disease associated with SLE and vasculitis is another feature which indicates a more aggressive diagnostic approach in the management of GN in our area.

Copyright (C) 1999 S. Karger AG, Basel

\section{Introduction}

Contrary to adults, data on the clinical, pathological, and epidemiological features of glomerulonephritis (GN) in children are limited. Multiple factors have contributed negatively to such a phenomenon, of which the slow emerging status of pediatric nephrology as an independent subspecialty, as compared with the adult one, and the limitations akin to kidney biopsy in children are of paramount importance. The latter, though was seriously affected by the former, remained a major handicap in the assessment and management of these sick children. The high proportion $(>85 \%)$ of children with steroid-responsive 'idiopathic' nephrotic syndrome (NS) and the need for an experienced operator, radiological assistance, and general anesthesia in younger children were cogent arguments in favor of limiting such an invasive procedure to those who manifest steroid refractoriness [1] or signs of secondary GN. Data on these forms of GN are slowly emerging from different societies [2], though most have been affected by the limited number of cases studied, referral bias of tertiary centers, difference in biopsy indications, admixture of different populations, and limited area of coverage [36]. The present study was conducted to examine the clinical, pathological, and epidemiological features of these forms of $\mathrm{GN}$ in the Kuwaiti children and compare these to those previously reported from Kuwait and other parts of the world.

\section{Patients and Methods}

Kuwait is an Asian country located on the northeastern part of the Arabian peninsula and has an area of $17,818 \mathrm{~km}^{2}$ (6,960 square miles). In mid-1993, it had a population of 1.4 million, of which 0.62 million $(43 \%)$ were Kuwaiti nationals. In the latter group, 254,976 were $\leq 14$ years old. In these Kuwaiti children, the male:female ratio was 1:1.

\section{Study Design}

Data on children referred for the management of GN, excluding kidney transplant patients, who were seen at the A1-Amiri and the Mubarak Al-Kabeer hospitals were collected retrospectively in December 1996. These hospitals are the two teaching hospitals of the Kuwait University, and their renal centers are the only facilities specialized for the care of both adult and childhood renal diseases. The study period covered 7 years, from January 1, 1990, to December 31, 1996. Children were included in the study if they had: (1) steroid-refractory idiopathic GN (SRIGN), i.e., those who failed the 8-week course of prednisone therapy (see below) or (2) a secondary form of GN.

\section{Clinical and Laboratory Data}

The data collected included: age of the patient at diagnosis of GN, sex and nationality, as well as the clinical manifestations of $\mathrm{GN}$ and its duration and response to corticosteroid therapy. Laboratory investigations included urinalysis, 24-hour urinary protein excretion, and creatinine clearance as well as serum cholesterol, complements (C3 and C4), immunoglobulins, antinuclear antibody, antid-DNA, antineutrophil cytoplasmic autoantibody, hepatitis B surface antigen, hepatitis $\mathrm{C}$ virus antibodies, ASOT, and rheumatoid factor. Histological diagnosis of GN was made based on the results of: (1) light microscopic examination of $2-\mu \mathrm{m}$ sections of renal tissues which were stained with hematoxylin and eosin, periodic acid-Schiff, Masson's trichrome, and periodic acid-silver methenamine; (2) immunofluorescence using antisera against $\mathrm{C} 3$, fibrinogen, and immunoglobulins (IgA, IgM and $\operatorname{IgG}$ ), and (3) electron microscopy in selected patients.

\section{Indications for Kidney Biopsy}

Over the past 7 years, all patients who were referred to the two renal centers were considered for kidney biopsy, if they manifested one of the following criteria: (1) NS (persistent proteinuria $>40 \mathrm{mg} / \mathrm{h} / \mathrm{m}^{2}$ ) which failed to respond to an 8-week course of prednisone ( $2 \mathrm{mg} / \mathrm{kg}$ every $2 \mathrm{nd}$ day); (2) persistent proteinuria of any degree $\left(>4 \mathrm{mg} / \mathrm{h} / \mathrm{m}^{2}\right)$ with unexplained hematuria;

Med Principles Pract 1999;8:328-333 329 
Table 1. Clinical features of children with GN in Kuwait (1990-1996)

\begin{tabular}{|c|c|c|c|c|c|c|c|c|c|c|}
\hline \multirow[t]{2}{*}{ Diagnosis } & \multirow{2}{*}{$\begin{array}{l}\text { Number } \\
\text { of } \\
\text { patients }\end{array}$} & \multicolumn{2}{|c|}{ Male/female ratio } & \multicolumn{3}{|c|}{ Signs of renal disease } & \multicolumn{4}{|c|}{ Clinical presentation at diagnosis } \\
\hline & & Kuwaiti & $\begin{array}{l}\text { non- } \\
\text { Kuwaiti }\end{array}$ & $\begin{array}{l}\text { hyper- } \\
\text { tension }\end{array}$ & $\begin{array}{l}\text { protein- } \\
\text { uria }\end{array}$ & $\begin{array}{l}\text { hema- } \\
\text { turia }\end{array}$ & NS & $\begin{array}{l}\text { rapidly } \\
\text { progr. renal } \\
\text { failure }\end{array}$ & $\begin{array}{l}\text { chronic } \\
\text { renal } \\
\text { failure }\end{array}$ & $\begin{array}{l}\text { multi- } \\
\text { system } \\
\text { disease }\end{array}$ \\
\hline \multicolumn{11}{|l|}{ Idiopathic nephrotic syndrome } \\
\hline Minimal-change disease & 33 & $13 / 9$ & $7 / 4$ & 2 & 33 & 1 & 33 & 0 & 0 & 0 \\
\hline Focal segmental glomerulosclerosis & 6 & $3 / 2$ & $0 / 1$ & 4 & 6 & 4 & 5 & 1 & 0 & 0 \\
\hline \multicolumn{11}{|l|}{ Mesangioproliferative (non-IgA) } \\
\hline glomerulosclerosis & 5 & $1 / 1$ & $1 / 2$ & 3 & 5 & 3 & 4 & 0 & 0 & 0 \\
\hline Congenital nephrotic syndrome & 2 & $0 / 0$ & $1 / 1$ & 0 & 2 & 0 & 2 & 0 & 0 & 0 \\
\hline Membranous GN & 1 & $1 / 0$ & $0 / 0$ & 0 & 1 & 0 & 1 & 0 & 0 & 0 \\
\hline \multicolumn{11}{|l|}{ Secondary $G N$} \\
\hline SLE & 8 & $2 / 5$ & $0 / 1$ & 7 & 8 & 8 & 2 & 2 & 1 & 3 \\
\hline Vasculitis & 5 & $1 / 2$ & $0 / 2$ & 4 & 3 & 5 & 1 & 1 & 1 & 2 \\
\hline Poststreptococcal GN & 4 & $1 / 1$ & $1 / 1$ & 4 & 4 & 4 & 4 & 0 & 0 & 0 \\
\hline Immunoglobulin A glomerulopathy & 2 & $1 / 0$ & $1 / 0$ & 2 & 2 & 2 & 1 & 1 & 0 & 0 \\
\hline Henoch-Schönlein purpura & 2 & $1 / 1$ & $0 / 0$ & 2 & 2 & 2 & 2 & 0 & 0 & 0 \\
\hline Alport's disease & 1 & $1 / 0$ & $0 / 0$ & 1 & 1 & 1 & 0 & 0 & 1 & 0 \\
\hline \multicolumn{11}{|l|}{ Unclassified } \\
\hline Sclerosing GN & 2 & $1 / 1$ & $0 / 0$ & 2 & 2 & 1 & 2 & 0 & 0 & 0 \\
\hline Biopsy refused & 4 & $3 / 1$ & $0 / 0$ & 0 & 4 & 0 & 4 & 0 & 0 & 0 \\
\hline \multicolumn{11}{|l|}{ Bilateral small kidneys } \\
\hline (unbiopsied, yet GN suspected) & 5 & $3 / 1$ & $1 / 0$ & 3 & 5 & 5 & 2 & 0 & 1 & 0 \\
\hline Total & 80 & $32 / 24$ & $12 / 12$ & 34 & 75 & 33 & 63 & 5 & 6 & 5 \\
\hline
\end{tabular}

(3) isolated hematuria unexplained by hematological, renovascular, or urinary tract disease; (4) rapidly progressive renal failure (i.e., rapid decline in creatinine clearance over 3-6 weeks), and (5) unexplained renal failure with normal-sized kidneys.

\section{Results}

\section{Epidemiological Profile}

During the study period, a total of 80 children were diagnosed as having SRIGN or secondary GN, 56 of whom were Kuwaiti nationals (table 1). Forty-seven patients had histological and clinical evidence of SRIGN, 30 of whom were Kuwaiti nationals, and 22 had secondary forms of GN. Eleven patients had evidence of glomerulopathy, but were histologically unclassified. This group consisted of
2 patients with advanced sclerosing GN, 4 who refused kidney biopsy, and 5 who presented with bilateral small kidneys and yet had a history of NS. The 4 patients who refused kidney biopsy did not have systemic manifestations of autoimmune disease, extrarenal systemic involvement, renal failure, or abnormal urinalysis. For analysis purposes, and based on these clinical criteria as well as their presentation as a frequently relapsing NS, the latter 4 patients were included in the study as having idiopathic NS. Hence, the calculated average annual incidence rate of $\mathrm{Ku}$ waiti children with SRIGN and secondary GN was 3.1 per million and that of SRINS alone was 1.9 per million for Kuwaiti children. In Kuwaiti nationals, males were 1.3 times the females. When the distribution of patients, according to their diagnosis, was 


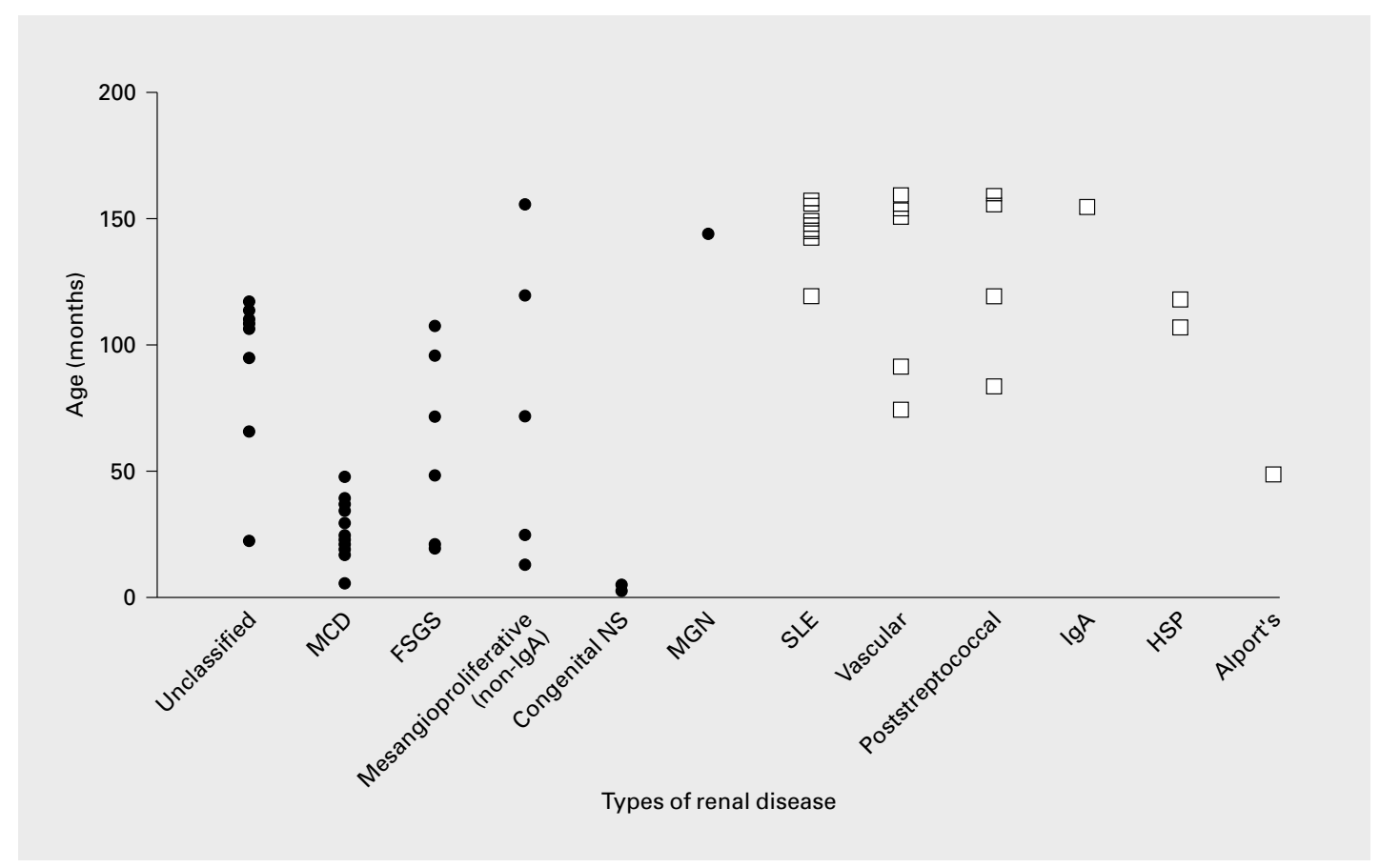

Fig. 1. Scatter diagram showing the age distribution of children with $G N$ according to the histological type. - Idiopathic nephrotic syndrome; $\square=$ secondary forms of GN. MCD = Minimal-change disease; FSGS = focal segmental glomerulosclerosis; MGN = membranoproliferative GN; HSP = Henoch-Schönlein purpura.

plotted against their respective age at the time of diagnosis, none of the patients with secondary forms of GN, except for 1 patient with Alport's syndrome, presented before the age of 60 months (fig. 1).

\section{Etiology of GN}

The underlying renal disease in all patients is shown in table 1 . In the Kuwaiti nationals, 34 patients $(61 \%)$ were classified as having SRIGN, 30 of whom underwent renal biopsy. Histologically, $22(65 \%)$ of these patients were classified as having minimal-change NS, $5(16 \%)$ as having focal segmental glomerulosclerosis, 2 (6\%) as having non-IgA mesangioproliferative GN, and 1 as having membranous GN. After the exclusion of 1 patient with
Alport's syndrome, 14 of the 15 patients studied presented with NS with or without renal failure. Aggressive autoimmune diseases such as systemic lupus erythematosus (SLE) and vasculitis were common. Seven patients had SLE which accounted for $44 \%$ of secondary GN and for $14 \%$ of all patients studied, while 3 patients were found to have vasculitis. In general, congenital NS and membranoproliferative GN were not seen in the Kuwaiti children, and NS secondary to IgA glomerulopathy was diagnosed in 1 patient only. During our study, parasitic infestations or microbial infections such as malaria, leishmaniasis, schistosomiasis, tuberculosis, brucellosis, hepatitis B or C, and congenital syphilis were not seen in our Kuwaiti patients. 


\section{Clinicopathological Correlations}

The spectrum of renal disease associated with SRIGN and secondary forms of GN is summarized in table 1. NS was the presenting feature of all patients with SRIGN, except for 1 patient with focal segmental glomerulosclerosis who presented with persistent proteinuria $\left(32 \mathrm{mg} / \mathrm{h} / \mathrm{m}^{2}\right)$, hematuria, and rapidly progressive renal failure. Hypertension and hematuria were rarely encountered in patients with minimal-change disease, in contrast to patients with focal segmental glomerulosclerosis and mesangioproliferative GN (67 and $60 \%$, respectively). On the other hand, 10 of the 22 patients with secondary forms of GN presented with NS, and most had hypertension and hematuria. Interestingly, only 3 of the 13 patients with SLE and vasculitis presented rapidly progressive renal failure and 5 with multisystem disease.

\section{Discussion}

In the present study, a total of 56 Kuwaiti children were diagnosed to have either SRIGN or secondary forms of GN over the past 7 years. The study was not designed to be representative of all GN in Kuwaiti children for two reasons: (1) as in any similar studies conducted in tertiary units, patients with mild forms of GN may escape inclusion due to underdiagnosis or failure to report, and (2) children in whom the diagnosis of NS has been made, clinically as idiopathic, based on the absence of risk factors (hypertension, hematuria, raised serum creatinine, low plasma C3) and manifested cure of infrequent relapses after corticosteroid therapy by their primary pediatrician may be difficult to follow in any retrospective study $[1,7]$. For these reasons, the study concentrated on children with SRIGN and those with severe forms of secondary GN, in whom alternatives to the conventional 8-week corticosteroid therapy are to be used and the risk of complications of the disease or side effects of therapy requires specialized care. Moreover, the management of the latter group of patients, due to their high rate of short- and long-term morbidity [8], is a major health concern, both financially and socially. Our study has covered the whole country of Kuwait and excluded the 'unstable' expatriate population. Moreover, the liberal policy of the referral to the specialized centers and the free-of-cost management to all social strata have helped to generate our results which should reflect the true pattern of the epidemiological characteristics of refractory GN in Kuwaiti children. Our observation of an annual incidence rate of 1.9 Kuwaiti children with SRIGN per 100,000 is nearly double that reported from an earlier study from Kuwait [3]. Our study is more likely to be representative of the true incidence of SRIGN in Kuwait, since the previous study was conducted in a general hospital on the outskirts of Kuwait and covered two undefined population areas. Furthermore, in the former study, children from other Arab states were included in the analysis. Such a methodology may have been responsible for the difference in the histological diagnosis of their 9 patients with SRIGN as compared with our study. In the former study, 5 out of 9 children with SRIGN had membranoproliferative GN, while this GN was not seen in any Kuwaiti children over 7 years of observation. This form of GN has been reported with relatively higher frequency in Arab patients from the Mediterranean countries [9] and in those with infections such as hepatitis (B and C) [10, 11], malaria [12], and schistosomiasis $[13,14]$. In the Iranian experience [5], membranoproliferative GN was diagnosed in 80 of their 411 patients (19\%) with GN as compared with 2 in the 25 patients $(8 \%)$ in the Saudi children [4]. In our study, minimal-change GN was the most 
frequent histological diagnosis in patients with SRIGN in general, while focal segmental glomerulosclerosis was the predominant lesion in those who manifested steroid resistance. These features may have been different from those reported in the Irani and Saudi studies $[4,5]$, yet are similar to those described by Churg et al. [15] and McEnery et al. [16] in a North American population.

The spectrum of secondary GN in Kuwaiti children is interesting. Though the incidence of certain GN such as postinfectious and benign hematuria syndromes may have been underestimated for methodological reasons, that of others such as lupus nephritis and renal vasculitis was not. The latter two GN were not rare and accounted for $17 \%$ of the total GN referred for management. Though these entities were reported as uncommon GN in Western countries $[15,16]$, SLE was seen in 33 of the 411 patients (8\%) subjected to kidney biopsy in Iran and vasculitis in 9 (2\%) [5]. The relatively higher incidence of these two forms of GN may have been a reflection of ethnic predisposition, yet the higher incidence of patients with kidney-limited lupus and vasculitis as well as the presentation of NS in 3 patients are disturbing findings. The latter two findings may have been the result of a better surveillance in our study population, yet they provide a cogent argument in favor of adopting an aggressive diagnostic approach in the management of childhood GN.

\section{References}

1 International Study of Kidney Disease in Children: The primary nephrotic syndrome in children: Identification of patients with minimal change nephrotic syndrome from initial response to prednisone. J Pediatr 1981;98:561-564.

2 Glassock RJ, Cohen AH, Adler SG: Primary glomerular diseases; in Brenner BM, Rector FC (eds): The Kidney. Philadelphia, Saunders, 1996, pp 1392-1497.

3 Zaki M, Helin I, Manadhar DS, Hunt MC, Khalil AF: Primary nephrotic syndrome in Arab children in Kuwait. Pediatr Nephrol 1989;3: 218-220.

4 Abduvrahman MB, El-Idrissy AT, Hafeez MA, Wright EA, Omar SA: Renal biopsy in Saudi children with nephrotic syndrome not responsive to corticosteroid: A preliminary report. Trop Geogr Med 1986;38: 141-145.

5 Bodaghi E, Vazirian S, Abtahi M, Honarmand MT, Madani A, Zia Shamsa AM: Glomerular disease inchildren. 'The Iranian Experience'. Pediatr Nephrol 1989;3:213-217.
6 Valderrabano FC, Berthoux FC, Jones EHP, Mehls O: Report on management of renal failure in children in Europe XXV, 1994, and stage renal disease and dialysis report. Nephrol Dial Transplant 1996; 11(suppl 1):2-21.

7 Neuhaus TJ, Fay J, Dillon MJ, Trompeter RS, Barratt TM: Alternative treatment of corticosteroids in steroid-sensitive idiopathic nephrotic syndrome. Arch Dis Child 1994; 71:522-526.

8 Mendoza SA, Tune BM: Management of the difficult nephrotic patient. Pediatr Clin North Am 1995; 42:1459-1471.

9 Essamie MA, Soliman A, Fayed TM, Barsoum S, Kjellstrand CM: Serious renal disease in Egypt. Int J Artif Organs 1995;18:254-260.

10 Johnson RJ, Couser WG: Hepatitis $\mathrm{B}$ infection and renal disease: Clinical, immunopathogenetic and therapeutic considerations. Kidney Int 1990;37:663-676.
11 Johnson RJ, Gretch DR, Yamabe $\mathrm{H}$, et al: Membranoproliferative glomerulonephritis associated with hepatitis $\mathrm{C}$ virus infection. $\mathrm{N}$ Engl $\mathrm{J}$ Med 1993;328:465-470.

12 Chugh KS, Sakhnja V: Glomerular diseases in the tropics. Am J Nephrol 1990;10:437-450.

13 Barsoum RS: Schistosomal glomerulopathies. Kidney Int 1993;44: 112.

14 Queiroz FB, Brito E, Martinelli R: Influence of regional factors in the distribution of histologic patterns of glomerulonephritis in the nephrotic syndrome. Nephron 1975;14:466470 .

15 Churg J, Habib R, White RH: Pathology of nephrotic syndrome in children. Lancet 1970;i:1299-1302.

16 McEnery PT, Alexander SR, Sullivan $\mathrm{K}$, Tejani A: Renal transplantation in children and adolescents: The 1992 Annual Report of the North American Pediatric Renal Transplantation Cooperative Study. Pediatr Nephrol 1993;7:711-720. 